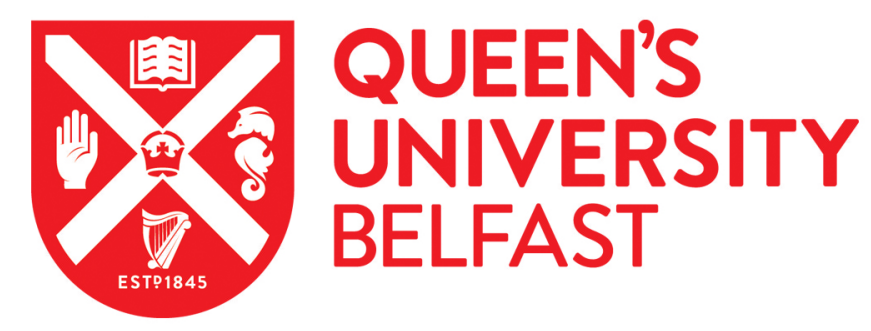

\title{
Efficiency of starfish mopping in reducing predation on cultivated benthic mussels (Mytilus edulis Linnaeus)
}

Calderwood, J., O'Connor, N. E., \& Roberts, D. (2016). Efficiency of starfish mopping in reducing predation on cultivated benthic mussels (Mytilus edulis Linnaeus). Aquaculture, 452, 88-96.

https://doi.org/10.1016/j.aquaculture.2015.10.024

\section{Published in:}

Aquaculture

Document Version:

Peer reviewed version

Queen's University Belfast - Research Portal:

Link to publication record in Queen's University Belfast Research Portal

\section{Publisher rights}

(C) 2015 Elsevier Ltd

This is an open access article published under a Creative Commons Attribution-NonCommercial-NoDerivs License

(https://creativecommons.org/licenses/by-nc-nd/4.0/), which permits distribution and reproduction for non-commercial purposes, provided the author and source are cited

\section{General rights}

Copyright for the publications made accessible via the Queen's University Belfast Research Portal is retained by the author(s) and / or other copyright owners and it is a condition of accessing these publications that users recognise and abide by the legal requirements associated with these rights.

Take down policy

The Research Portal is Queen's institutional repository that provides access to Queen's research output. Every effort has been made to ensure that content in the Research Portal does not infringe any person's rights, or applicable UK laws. If you discover content in the Research Portal that you believe breaches copyright or violates any law, please contact openaccess@qub.ac.uk. 


\section{Accepted Manuscript}

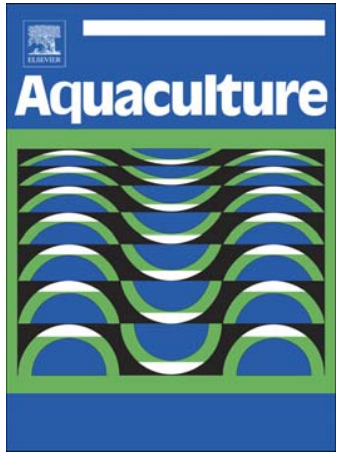

Efficiency of starfish mopping in reducing predation on cultivated benthic mussels (Mytilus edulis Linnaeus)

Julia Calderwood, Nessa E. O'Connor, Dai Roberts

PII:

S0044-8486(15)30213-1

DOI:

doi: 10.1016/j.aquaculture.2015.10.024

Reference: $\quad$ AQUA 631883

To appear in: $\quad$ Aquaculture

Received date: 17 June 2015

Revised date: $\quad 10$ October 2015

Accepted date: 18 October 2015

Please cite this article as: Calderwood, Julia, O'Connor, Nessa E., Roberts, Dai, Efficiency of starfish mopping in reducing predation on cultivated benthic mussels (Mytilus edulis Linnaeus), Aquaculture (2015), doi: 10.1016/j.aquaculture.2015.10.024

This is a PDF file of an unedited manuscript that has been accepted for publication. As a service to our customers we are providing this early version of the manuscript. The manuscript will undergo copyediting, typesetting, and review of the resulting proof before it is published in its final form. Please note that during the production process errors may be discovered which could affect the content, and all legal disclaimers that apply to the journal pertain. 
Efficiency of starfish mopping in reducing predation on cultivated benthic mussels (Mytilus edulis Linnaeus).

Julia Calderwood $^{\text {ab*, Nessa E. O'Connor }}{ }^{\text {abc, }}$, Dai Roberts ${ }^{\text {ab }}$

aQueen's University Marine Laboratory, 12-13 The Strand, Portaferry, Co. Down, Northern Ireland, BT22 1PF, UK

${ }^{\mathrm{b}}$ School of Biological Sciences, Medical Biology Centre, Queen's University Belfast, 97 Lisburn Road, Belfast, BT9 7BL, UK

'Institute of Global Food Security, Queen's University Belfast,18-30 Malone Road, Belfast, BT9 5BN, UK

*Corresponding author:

E-mail address: jcalderwood05@qub.ac.uk 


\section{Abstract}

The starfish, Asterias rubens, preys on mussels (Mytilus edulis), which are relaid during benthic cultivation processes. Starfish mops, a modified dredge used to remove starfish from mussel cultivation beds, are used in several fisheries today but few studies have attempted to quantify the effectiveness of this method in removing starfish. This study tested the effectiveness of starfish mopping to reduce starfish numbers on mussel beds in Belfast Lough, Northern Ireland. Video surveys to determine starfish densities on mussel beds were conducted between October 2013 and December 2014 using a GoPro ${ }^{\mathrm{TM}}$ camera attached to starfish mops. This allowed us to firstly test whether starfish density varied among mussel beds and to investigate how fluctuations in starfish numbers may vary in relationship to starfish ecology. We then estimated the efficiency of mops at removing starfish from mussel beds by comparing densities of starfish on beds, as determined using video footage, with densities removed by mops. Starfish abundance was similar among different mussel beds during this study. The efficiency of mops at removing estimated starfish aggregations varied among mussel beds $(4-78 \%)$ and the mean reduction in starfish abundance was $27 \%( \pm \mathrm{SE}$ 3.2). The effectiveness of mops at reducing starfish abundance was shown to decline as the initial density of starfish on mussel beds increased. It can be recommended that the exact deployment technique of mops on mussel beds should vary depending on the density of starfish locally. The area of mussel bed covered by mops during a tow, for example, should be less when starfish densities are high, to maintain efficiencies throughout the full length of tows and to optimise the removal of starfish from mussel beds. This strategy, by reducing abundance of a major predator, could assist in reducing losses in the mussel cultivation industry.

Key words; Asterias rubens, Mytilus edulis, predation, starfish mop, aquaculture, fisheries 


\section{$1 \quad$ Introduction}

Starfish are frequently described as keystone species, acting as major predators within subtidal and intertidal communities (Aguera et al., 2012; Himmelman et al., 2005; Paine, 1966). Asterias rubens, a starfish with a distribution ranging from Arctic to Boreal regions, is an important component of soft bottom benthic communities throughout Europe (Anger et al., 1977; Guillou, 1996; Nichols and Barker, 1984). It is an opportunistic and voracious predator with the ability to feed on a variety of crustaceans, molluscs and echinoderms, utilising chemoreception and chemically mediated prey location to find suitable food sources (Hancock, 1955; Sloan, 1980). A. rubens, along with several other starfish species within the genus Asterias, exhibit large population density fluctuations and are known to form dense aggregations (Sloan, 1980; Uthicke et al., 2009). High densities of A. rubens have frequently been reported at numerous locations across Europe and Russia since a dense aggregation was first reported, feeding on oyster beds, in the Firth of Forth, Scotland in 1841 (Dare, 1982, 1973; Forbes, 1841; Guillou, 1996; Hancock, 1955; Saier, 2001; Sloan and Aldridge, 1981; Sloan, 1980). These dense starfish populations are often associated with an abundant prey source and are known to have significant impacts on associated communities (Aguera et al., 2012; Castilla, 1972; Uthicke et al., 2009).

During the benthic cultivation of mussels (Mytilus edulis) small seed mussels are collected from high density offshore sites where there is competition for food and space, and are returned to sheltered inshore sites with a good food supply where they are spread at lower densities and grow to a marketable size within approximately two years (McQuaid et al., 2007; Smaal, 2002). Mussel cultivation sites can occupy large areas with mussels often being relaid at densities of between 25 and 75 tonnes per hectare (McQuaid et al., 2007). Mussels, when relaid on the seabed as part of benthic cultivation operations, thus, provide starfish with an abundance of prey in their natural environment (Barbeau et al., 1998; Miron et al., 2005). Consequently marine farming activities may influence the size and dynamics of aggregating starfish populations (Inglis and Gust, 2003). Observations of dense 
aggregations of starfish moving towards prey sources have noted particularly high densities of individuals within feeding fronts with 47 and 78 starfish $\mathrm{m}^{-2}$ being recorded on mussel beds in Morecambe Bay and the Wadden Sea respectively (Aguera et al., 2012; Dare, 1982; Saier, 2001). Starfish within such dense populations act as highly efficient predators, increasing their consumption when they encounter high-density prey patches, with aggregations in Morecambe Bay having been noted to advance up to $200 \mathrm{~m}$ a month destroying mussel beds that lay in their path (Dare, 1982; Inglis and Gust, 2003). A rubens is thought to be one of the most destructive species feeding on beds of cultivated mussels, as well as on natural populations, in northern Europe (Dare, 1982; Gallagher et al., 2008).

In areas where starfish occur in high densities it is often deemed necessary for these predators to be removed from mussel beds to help reduce losses within the benthic cultivation industry. The use of baited crab pots, as used to remove predatory crabs from mussel beds, have also been shown to attract starfish in some areas (Calderwood et al., 2015). Thus there may be an additional need to tackle and reduce inflated starfish numbers in areas where pots are deployed. Individual starfish typically consume around 0.5 mussel per day although maximum feeding rates of 0.8 mussels per hour have been recorded for larger individuals (Aguera et al., 2012; Calderwood et al., 2015; Kamermans et al., 2009; Bettina Saier, 2001; Vevers, 1949). In areas, such as Menai Straits, Wales, where benthic mussel cultivation occurs with starfish densities of $4 \mathrm{~m}^{-2}$, it is estimated that starfish are responsible for removing at least 20,000 mussels per hectare per day (Gallagher et al., 2008). American shellfish growers have attempted to control starfish populations since the middle of the $19^{\text {th }}$ century through the adoption of numerous methods (Barkhouse et al., 2007; Galtsoff and Loosanoff, 1939; Lee, 1951). A number of mechanical methods have been used including the use of dredges and suction dredges in areas with particularly high concentrations of starfish (Galtsoff and Loosanoff, 1939). Another common control measure is the use of starfish tangles or mops. Although the exact design can vary, starfish mops generally consist of a modified dredge which has a number of lengths of chain, attached at regular intervals perpendicular to the dredge bar, onto which are attached small sections of knotted and frayed rope (Fig. 1). Mops are slowly dragged across the surface of mussel and oyster beds, 
starfish become entangled in the ropes and the mops are raised to the surface where starfish are removed from the mops by hand (Galtsoff and Loosanoff, 1939; Lee, 1951; G. F. M. Smith, 1940). Dredgers usually move forwards and backwards over aquaculture plots, deploying mops from alternating sides of the ship, in an attempt to clear areas of starfish. Mopping is thought to result in less damage to shellfish beds compared to dredging and be generally more efficient, depending on substratum type and working conditions, although little work has been done to determine the exact efficiency of such starfish removal techniques (Barkhouse et al., 2007; Galtsoff and Loosanoff, 1939).

Despite uncertainty of effectiveness these mopping techniques are still widely used in the benthic mussel cultivation industry in an attempt to remove starfish from cultivation beds. Although mops appear to remove starfish from mussel beds, there is scope to enhance efficiency. In addition, there is a need to better understand starfish population dynamics and feeding behaviour in relation to environmental factors and reproductive condition to help determine how mopping efforts could be more cost-effectively focussed both spatially and temporally (Calderwood et al., 2015; Dare, 1982; Gallagher et al., 2008; Sloan and Aldridge, 1981). By attaching a GoPro ${ }^{\mathrm{TM}}$ video camera to starfish mops on a commercial mussel dredger working in Belfast Lough, Northern Ireland, we filmed the mussel bed being swept by the mops. We tested whether the population structure and abundance of starfish on mussel beds differed with: (i) date of mopping; (ii) size of mussels on mussel beds; and (iii) the reproductive condition of starfish on the mussel beds. We also examined whether the efficiency of mops differed with: (i) date of mopping; (ii) size of mussels on mussel beds; (iii) reproductive condition of starfish on mussel beds; and (iv) initial density of starfish on mussel bed being mopped.

\section{$2 \quad$ Methods}

\subsection{Survey and sampling methods}

Work was conducted on subtidal mussel beds at Belfast Lough on the east coast of Northern Ireland (Fig. 2). Belfast Lough is a shallow semi-enclosed bay (approx. area $=130 \mathrm{~km}^{2}$ ) with a mean salinity of 28 and water temperatures ranging between 2 and $21^{\circ} \mathrm{C}$ throughout the year (AFBI, 2014). Despite 
Belfast Lough containing a major port and shipping channel, to accommodate freight and passenger vessel traffic, greater than $7 \%$ of the lough is occupied by mussel aquaculture (Ferreira et al., 2008). Here work was carried out on an area licensed for benthic mussel culture (Fig. 2; 54 40 $36.82^{\prime \prime} \mathrm{N} ; 5^{\circ}$ 51 '33.76" W) across approximately 30 hectares, with an average depth of $4.5 \mathrm{~m}$ (chart datum) This area consisted of numerous individual mussel beds with mussels at all stages of the cultivation process from point of relaying of seed mussels to mussels ready for harvest.

Work was conducted on-board a commercial mussel dredger operating within Belfast Lough. Sampling took place between October 2013 and December 2014, and was opportunistic depending on when the dredger was scheduled to mop for starfish, which was restricted by weather and the requirement of the dredger and crew to perform other duties within the mussel fishery, with a total of nine sampling events within this period. Due to time constraints it was also not possible to conduct surveys on every mopping trip that was undertaken by mussel cultivators during this period and some starfish mopping inevitably went unmonitored. When mopping for starfish was monitored two mops consisting of a $6 \mathrm{~m}$ long dredge bar, from which 40 lengths of chain ( $2 \mathrm{~m}$ in length), positioned at $15 \mathrm{~cm}$ intervals and to which lengths of frayed rope are attached (Fig. 1), were towed alternatively from each side of the ship in a to and fro manner across the mussel bed. The length of tows ranged from $400 \mathrm{~m}$ to $900 \mathrm{~m}$ with the mussel dredger travelling at a mean speed of 1.75 knots \pm 0.08 whilst mopping. A GoPro ${ }^{\mathrm{TM}}$ camera (GoPro, USA) was attached to the apex of the starfish mop deployed from the starboard side of the ship, with the camera orientated towards the direction of the travel of the mop so that it could view the area of seabed about to be mopped (Fig. 1). The start and end positions of each mop tow, to which the camera was attached, was noted from the ship's GPS positioning software (Furuno, Japan). When the mop was lowered to the seabed the camera was at a height of approximately $28 \mathrm{~cm}$ above the sea bed, providing a $75 \mathrm{~cm}$ wide view along the bottom edge of recorded footage. Owing to high water turbidity and reduced visibility on sampling events in April and November 2014, video footage recorded was not suitable for analysis. Videos from a total of 31 tows conducted on remaining sampling dates were analysed to determine starfish densities observed on mussel beds depending on underwater visibility and camera battery life (Table 1). Due to the 
constraints encountered whilst working from a commercial mussel dredger it was not possible to further validate this video survey technique. The versatile nature of the GoPro ${ }^{\mathrm{TM}}$ camera did, however, allow us to opportunistically gather important information with regard to best mopping practise.

When the starboard mop, to which the camera was attached, was returned on-board after a tow all starfish were removed from the mop by hand. The number of starfish collected was recorded and the length of the longest arm of every $5^{\text {th }}$ individual was measured using callipers (precision $0.1 \mathrm{~mm}$ ) and recorded. To assess the population structure of the starfish on mussel beds the abundance and size of starfish collected by mops was recorded from a total of 81 tows, including the additional tows where recorded video footage was not suitable for analysis (Table 1). The reproductive condition of starfish was also assessed to examine possible relationships between spawning periods, the movement of starfish and the potential variability in feeding rate experienced during the reproductive cycle (Gallagher et al., 2008; Hancock, 1955; Ventura et al., 1997). Twenty starfish were selected randomly from mop tows at each sampling date and the longest arm length (precision $0.1 \mathrm{~mm}$ ) and biomass (precision $0.01 \mathrm{~g}$ ) of each starfish was recorded. Starfish were dissected aborally by making an incision along the mid line of each arm. The gonads and pyloric ceaca were removed and the wet weight of each was recorded. The gonad and pyloric caecum weights were converted to organ indices (organ weight/total starfish weight $\mathrm{x}$ 100) to normalize values, thus allowing for comparisons between individuals (Franz, 1986; Giese, 1966).

\subsection{Video and Data Analysis}

The length of each mopping tow was calculated using start and end positions. The number of starfish observed on the video for each individual tow was recorded to calculate the abundance of starfish per $\mathrm{m}^{2}$ on mussel beds prior to mopping (number of starfish observed/(width of field of view of video $\mathrm{x}$ length of transect)). The number of starfish removed by mops per $\mathrm{m}^{2}$ of bed mopped was also calculated (number of starfish removed from mop/(width of mop $(6 \mathrm{~m}) \mathrm{x}$ length of transect)). The 
efficiency of the mop was then calculated as a percentage of starfish collected per $\mathrm{m}^{2}$ compared to those observed per $\mathrm{m}^{2}$

Size distributions of $A$. rubens sampled from mops deployed at different times of the year and on different mussel beds were compared using pair-wise Kolomogorov-Smirnov tests with a Bonferroni correction to allow for multiple tests of significance being conducted (Scheiner, 2001; Simes, 1986). A log-linear regression was performed to compare density of starfish observed on videos with the density of starfish collected by mops to assess effectiveness of this predator removal technique. Density of starfish recorded in videos, density of starfish collected on mops and the efficiency of mops were analysed using analysis of variance (ANOVA) to test for differences among dates of deployment (nine levels; Oct 2013, Jan 2014, Mar 2014, Apr 2014, May 2014, Jul 2014, Oct 2014, Nov 2014, Dec 2014) and the size of mussels on mussel beds being mopped (six levels; 2000, 1500, $1350,800,600$ and 70 mussels $\mathrm{kg}_{-1}$ ). Data were tested for normality and homogeneity of variance prior to analysis using Shapiro-Wilk and Levene's tests as appropriate. Data did not, however, meet the assumptions of the statistical analyses and were, therefore, log transformed prior to analyses. Variation in reproductive condition of collected starfish over time of deployment (eight levels; Jan 2014, Mar 2014, Apr 2014, May 2014, Jul 2014, Oct 2014, Nov 2014, Dec 2014) was tested. Pyloric caeca indices were square root transformed to meet the assumptions of the statistical analysis before being analysed using ANOVA. Gonad indices did not conform to the assumptions of ANOVA even following transformation and were analysed using a generalised linear mixed model (GLMM) based on a gamma distribution and inverse link function (Zuur et al., 2009) due to their positive skew. Posthoc Tukey tests were used to make comparisons among levels of significant terms. All statistical analysis were undertaken in R (R Core Team, 2012).

\section{$3 \quad$ Results}


The population structure of starfish removed by mops differed over time (Fig. 3). Results from Kolomogorov-Smirnov tests showed that there was no difference in the size structure of starfish mopped from beds in April and May. January and July also had similar population structures and the results from December did not vary from January or October 2014. All other results were significantly different from each other. From March through to May there was a peak in smaller size classes of starfish being collected from beds. The smallest mean starfish arm length of $45.3 \mathrm{~mm} \pm 0.4$ was recorded in April. From July through to the end of 2014 there was a shift towards larger size classes of starfish being collected with a peak in October 2014 when the mean arm length of starfish removed from beds was $69.5 \mathrm{~mm} \pm 0.4$. The population structure of starfish collected by mops on beds of different mussel size also differed (Fig. 4). There was no significant difference between the population structure of starfish mopped from beds where the size of mussels was 2000 and 800 mussels kg-1. Otherwise the population structure of starfish differed between all remaining beds (Fig. 4). The mean arm length of starfish was smallest on beds with the two smallest size classes of mussels (2000 and 1500 mussels $\mathrm{kg}_{-1}$ ) with values of $48.4 \mathrm{~mm} \pm 1.6$ and $43.8 \pm 1.7$ respectively. As the mussels on beds became larger, the starfish associated with them also increased in size with the highest mean arm length of starfish $=72.8 \mathrm{~mm} \pm 1.9$ on beds with 800 mussels $\mathrm{kg}_{-1}$. On the beds with the largest mussels there was again a slight shift towards smaller size classes of starfish being collected by mops.

Reproductive condition (gonad index) varied with time $\left(\chi^{2}=3593.7, \mathrm{p}<0.001\right.$; Fig.5A). The gonad index peaked in April 2014 although post-hoc tests showed that there was no significant difference in reproductive condition from January through to May. Between May and July there was a dramatic drop in gonad index with it remaining low until November when it began to recover again (Fig. 5A). The pyloric caeca index also varied with time $\left(\mathrm{F}_{7,159}=28.911, \mathrm{p}<0.001 ;\right.$ Fig.5B $)$ generally displaying inverse relationship to the gonad index. The pyloric index peaked in July and remained stable for the remainder of the year with no significant difference between values recorded in January, October, November and December. A reduction in the pyloric index was evident between March and May with 
post-hoc tests showing results from these three months were lower than results collected during the rest of the year.

The density of starfish recorded on mussel beds by video differed temporally (Fig. 6; Table 2). A mean density of 0.5 starfish $\mathrm{m}^{-2} \pm 0.2$ was recorded in October 2013 which post-hoc tests showed differed significantly from all months other than January 2014. The greatest mean density of 0.8 starfish $\mathrm{m}^{-2} \pm 0.7$ was recorded in January 2014 , although owing to high variability this did not differ significantly from all other sampling dates. Following January, there was a considerable drop in the number of starfish observed on mussel beds with densities remaining low throughout the rest of the year. Post-hoc tests showed there was no difference in densities observed on beds from March to December 2014. The density of starfish collected by mops also differed temporally (Fig. 6; Table 1) and the lowest number of starfish were collected in May, July and December, with the results from these months all being similar to each other. A peak density was collected in October 2013 with a mean of 0.08 starfish $\mathrm{m}^{-2} \pm 0.01$ followed by a decrease to a minimum value in May 2014 with a mean of 0.01 starfish $\mathrm{m}^{-2} \pm 0.002$. Over the course of a year the average density of starfish observed on all mussel beds was 0.21 starfish $\mathrm{m}^{-2} \pm 0.05$.

The density of starfish recorded on mussel beds by video differed with mussel size (Fig. 7; Table 2). The highest density of starfish was found on mussel beds with 800 mussels $\mathrm{kg}^{-1}$, with a mean density of 0.5 starfish $\mathrm{m}^{-2} \pm 0.2$, which was significantly greater than the density of starfish viewed on mussel beds with 600 and 1500 mussels $\mathrm{kg}^{-1}$. There was no significant difference between starfish densities observed on any other mussel beds. Similarly the density of starfish collected by mops on mussel beds differed with mussel size (Fig. 7; Table 2) with the highest density of starfish being recovered from beds with 800 mussels $\mathrm{kg}^{-2}$ (mean density of starfish collected $=0.08$ starfish $\mathrm{m}^{2} \pm 0.01$ ). This was significantly different from the density collected from beds with 600 mussels $\mathrm{kg}^{-1}$ (mean density of starfish collected $=0.03$ starfish $\mathrm{m}^{2} \pm 0.008$ ), although there was no difference between the density of starfish collected from all other beds. Over the course of a year the average density of starfish observed on all mussel beds was 0.21 starfish $\mathrm{m}^{-2} \pm 0.05$. 
The relationship between the density of starfish collected by mop (DMop) and the density of starfish seen on video footage (DVideo) appears to be log-linear (Fig. 8) and is expressed in equation 1.

DMop $=0.0873+0.0233 \times \log ($ DVideo $)$

(equation 1)

$\mathrm{R}^{2}=0.51$

Although the efficiency of mops at removing starfish did show significant temporal variation (Fig. 6;

2) the density of starfish recorded on videos did not exactly track the density removed by mops over time. Mopping efficiency was greatest in October 2014 (mean $=44.9 \% \pm 8.9$ ), which was significantly greater than the mopping efficiency calculated for May and July, although there was no difference between efficiencies calculated for remaining dates.

\section{Discussion}

The economic necessity to control starfish populations on commercial shellfish beds has long been identified, with numerous starfish removal methods being adopted since the beginning of the $19^{\text {th }}$ century (Galtsoff and Loosanoff, 1939; Lee, 1951). Starfish mops are commonly used today in areas where starfish are known to be abundant. Despite the widespread use of this predator removal technique within mussel fisheries little work has been conducted to assess how effective it is at removing starfish from mussel beds. The efficiency of mops showed considerable variation with the percentage of starfish removed by mops compared to those viewed on video footage ranging from $4 \%$ to $78 \%$, with an average value of $27 \%$ ( \pm SE 3.2 ). If an understanding of population dynamics and ecology of starfish on mussel beds is improved, despite this variability in mopping efficiencies, the subsequent use of starfish mops may be optimised to increase starfish removal. 
There was little variation in the abundance of starfish observed on mussel beds in relation to the date of mopping activity. While relatively high densities of starfish were recorded on mussel beds on our first two sampling events in October 2013 and January 2014 the number of starfish observed remained low for the remainder of sampling in 2014. It has been noted that a reduction in chemoreceptive behaviour of $A$. rubens occurs during summer months whilst, conversely, maximum feeding rates have been associated with water temperatures between 10 and $13^{\circ} \mathrm{C}$, which occur in late spring and autumn in Belfast Lough (AFBI, 2014; Aguera et al., 2012; Castilla, 1972; Saier, 2001; Sloan, 1980). Such seasonal variation in food seeking and feeding behaviour may, therefore, influence the temporal movements of starfish on mussel beds in Belfast Lough. In addition, a reduction in feeding activity prior to spawning and a resumption of feeding following spawning, to replenish depleted energy reserves, has been identified in a number of starfish species (Hancock, 1955; Ventura et al., 1997). As such the reproductive cycle of starfish in Belfast lough could influence starfish movements and feeding behaviour. We could then expect greater densities of starfish on mussel beds in the late spring to early autumn. Our data, however, does not suggest that there were seasonal movements of starfish onto mussel beds when feeding and food-seeking behaviour may have been at an optimum. Additionally, extreme swarming behaviour, as has been noted previously for A. rubens (Sloan, 1980), was not observed in Belfast Lough during our sampling period. The greatest observed density of 1.48 starfish $\mathrm{m}^{-2}$, as recorded by video analysis, was considerably lower than the high densities recorded in swarming aggregations of starfish. Instead our results are more comparable to starfish densities identified previously on the subtidal mussel beds in the Menai Straits, Wales, which ranged from 0.8 to 4 starfish $\mathrm{m}^{-2}$ (Gallagher et al., 2008). Although densities observed in Belfast Lough are at the lower end of this range this could be as a result of regular mopping in this area successfully keeping starfish densities low by removal. Densities may also be reduced as a result of spreading starfish over mussel beds during mopping operations. Unfortunately, due to the opportunistic nature of sampling, it was not possible to determine the impact of continued, unmonitored starfish mopping on all mussels beds in Belfast lough during the study period and whether this was responsible for supressing starfish numbers. 
It was assumed that starfish collected by mops gave a good indication of the population structure of starfish on mussel beds that were mopped because the longest arm length of individuals collected covered a wide size range $(6 \mathrm{~mm}$ to $153 \mathrm{~mm})$. A variation in starfish size occurred on and among different beds on a temporal basis. Smaller size classes of starfish were more abundant on beds in March, April and May, coinciding with high gonad indices recorded during these months. As spawning was occurring during these months it is unlikely that the shift to smaller size classes of starfish was owing to recruitment. Larger starfish were more abundant on mussel beds later in the summer and autumn, possibly as a result of increased feeding during summer months resulting in growth of the starfish residing on mussel beds during this period (Vevers, 1949). Unfortunately, it was not possible to sample starfish from other locations within Belfast lough to determine whether starfish populations on the mussel beds studied were representative of other populations. Regardless of how representative the sampled starfish are of local populations the range of sizes of starfish collected throughout the year represent a population that is capable of consuming a large size range of mussels (Hummel et al., 2011; Kamermans et al., 2009; Sommer et al., 1999). This highlights the need for the adoption of predator removal techniques year round to reduce predatory pressures that may be placed on mussels by these starfish populations.

Despite there being no strong trend in density of starfish found on mussel beds in relation to mussel size there was some variation in the size structure of starfish populations collected from beds with different sizes of mussels. The prey size that starfish consume is limited by arm length and it may be expected that the size of starfish feeding on different sized mussels would vary (Anger et al., 1977). Although smaller size classes of starfish were more abundant on beds with the smallest sized mussels the starfish population on beds with 2000 mussels $\mathrm{kg}^{-1}$ did not differ from those found on beds with 800 mussels $\mathrm{kg}^{-1}$. While large starfish were more abundant on beds with the largest mussels (70 mussels $\mathrm{kg}^{-1}$ ), there was no difference between this and the population structure found on beds with 1500 mussels $\mathrm{kg}^{-1}$. It appears, therefore, that there is not a direct relationship between the size of starfish removed from beds and the size of mussels on which they may be feeding. There is evidence to show that starfish prefer smaller mussels compared to larger and more profitable mussels that might 
be within their consumable range (Hummel et al., 2011). Quality of prey may also be more important than size when starfish select what to feed on in order to maximise their net energy intake (Allen, 1983). Indeed Dolmer (1998) found little correlation between the size of A. rubens and the size of mussels preyed upon when studying the interaction of these two species following underwater surveys. It is also likely that smaller starfish removed from mussel beds could be feeding on other organisms that are associated with the matrix provided by cultivated mussel beds including fouling organisms such as barnacles (Saier, 2001; Sloan, 1980). With a large range of different sized starfish on all beds, mopping efforts should, therefore, be spread evenly between beds of mussels of different sizes if starfish populations are to be controlled.

The efficacy of the mops at removing starfish observed on mussel beds showed large variation, fluctuating between $4 \%$ and $78 \%$. A study conducted by Smith (1940), using a mark recapture method to assess the effectiveness of starfish mops, also showed considerable variation with $50 \%$ recapture following two hours of mopping in an area of $200 \mathrm{~m}^{2}$, reducing to $31 \%$ following three hours of mopping over an area of $4000 \mathrm{~m}^{2}$. We found seasonal variation in the effectiveness of mops at removing starfish from mussel beds as the density of A. rubens observed in videos increased. Once densities of 0.5 starfish $\mathrm{m}^{-2}$ were reached the effectiveness of mops showed a substantial decrease, possibly as a result of mops becoming saturated when large numbers of starfish were encountered. There was also a slight trend towards mops displaying greater effectiveness at removing starfish from beds with smaller sized mussels. This may be as a result of starfish being protected from mopping actions when they are within the structural matrix created by larger mussels compared to smaller mussels. Interestingly mopping efficiencies were lowest between May and July, which coincides with a fall in the gonad index and rise in the pyloric caeca index of starfish. Following spawning, starfish often resume feeding at an increased rate to replenish energy stores (Hancock, 1955; Ventura et al., 1997). If increased feeding activity was occurring during these months a greater proportion of starfish might be engaged in active feeding and be attached to prey items using their tube feet (Hancock, 1955). It may, therefore, be less likely that an individual starfish will become entangled in a mop if it 
is feeding as opposed to travelling or resting and thus mopping efficiencies are reduced during this period.

We demonstrated that mops remove starfish from mussel beds with a range of efficiencies although a mean of just $27 \%$ ( \pm SE 3.2) of starfish observed on mussel beds were removed by mops. We do, nonetheless, recognise that it would be beneficial to collect further information with regard to mopping operations to allow for the construction of a model to determine the exact effect that mopping has mussel yields and the economic output of such fisheries. If mopping operations were optimised further, however, this technique could be used to effectively remove larger numbers of starfish from mussel cultivation sites. With little seasonal variation being noted in the number of starfish recorded on beds it is important for mussel producers in Belfast Lough to continue mopping operations year round if starfish numbers are to be kept to a minimum. It may, however, be necessary to modify this strategy in Belfast lough and elsewhere by concentrating effort on mopping during times of the year when starfish are known to eat more, such as when water temperatures are between 10 and $13^{\circ} \mathrm{C}$ and following spawning. This is especially important because it may be more difficult to remove starfish from mussel beds when they are actively engaged in feeding. Additionally, mopping practices should be optimised by towing mops over shorter distances when high densities of A. rubens are encountered. Mops would then be recovered prior to becoming saturated with starfish, thus, maintaining mopping efficiencies throughout the entire length of tows. More intensive mopping on beds with larger size classes of mussels may also be required if a greater proportion of starfish are to be removed from these areas. Despite it not being possible to remove all starfish from mussel beds using mops, the improved understanding of starfish dynamics on mussel beds presented in this paper points to ways in which it is possible to achieve greater mopping efficiencies and further reduce predator numbers on mussel cultivation sites and potentially increase harvest to seed returns within the industry.

\section{Acknowledgements}


We thank Carrowholly Shellfish for allowing us to conduct work onboard their mussel dredgers with particular thanks to the crew of Emerald Gratia and Rona II. Thanks to N. Zwerschke and L. Eagling who provided valuable feedback on an early version of the manuscript. This research was funded by IBIS, project 2859 supported by the European Union's INTERREG IVA Programme managed by the Special EU Programmes Body (www.seupb.eu).

\section{References}

AFBI, 2014. Coastal Monitoring: Monitored Sites [WWW Document]. URL http://www.afbini.gov.uk/index/services/services-specialist-advice/coastal-science/coastalmonitoring/monitored-sites.htm (accessed 11.6.14).

Aguera, A., Trommelen, M., Burrows, F., Jansen, J.M., Schellekens, T., Smaal, A., 2012. Winter feeding activity of the common starfish (Asterias rubens $\mathrm{L}$.): The role of temperature and shading. Journal of Sea Research 72, 106-112.

Anger, K., Rogal, U., Schriever, G., Valentin, C., 1977. In-situ investigations on the echinoderm Asterias rubens as a predator of soft-bottom communities in the western Baltic Sea. Helgoland Marine Research 29, 439-459.

Barbeau, M.A., Scheibling, R.E., Hatcher, B.G., 1998. Behavioural responses of predatory crabs and sea stars to varying density of juvenile sea scallops. Aquaculture 169, 87-98.

Barkhouse, C.L., Niles, M., Davidson, L.A., 2007. A literature review of sea star control methods for bottom and off bottom shellfish cultures. Canadian Industry Report of Fisheries and Aquatic Sciences 279, $38 \mathrm{p}$.

Calderwood, J., O'Connor, N.E., Roberts, D., 2015. The effects of transportation stress and barnacle fouling on predation rates of starfish (Asterias rubens) on mussels (Mytilus edulis). Aquaculture.

Calderwood, Julia, O’Connor, Nessa E, Roberts, Dai, 2015. Effects of baited crab pots on cultivated mussel (Mytilus edulis) survival rates. ICES Journal of Marine Science: Journal du Conseil. doi:10.1093/icesjms/fsv043

Castilla, J.C., 1972. Response of Asterias rubens to bivalve prey in a Y-maze. Marine Biology 12, 222-228.

Dare, P.J., 1973. The stocks of young mussels in Morecambe Bay, Lancashire, in: Fisheries Information Leaflet No. 28. Ministry of Agriculture, Fisheries and Food, London, pp. 1-14.

Dare, P.J., 1982. Notes on the swarming behaviour and population density of Asterias rubens L. (Echinodermata: Asteroidea) feeding on the mussel, Mytilus edulis L. ICES Journal of Marine Science 40, 112-118. 
Ferreira, J.G., Hawkins, A.J.S., Monteiro, P., Moore, H., Service, M., Pascoe, P.L., Ramos, L., Sequeira, A., 2008. Integrated assessment of ecosystem-scale carrying capacity in shellfish growing areas. Aquaculture 275, 138-151. doi:10.1016/j.aquaculture.2007.12.018

Forbes, E., 1841. A history of British starfish and other animals of the class echinodermata. John Van Voorst, London.

Franz, D.R., 1986. Seasonal changes in pyloric caecum and gonad indices during the annual reproductive cycle in the seastar Asterias forbesi. Marine Biology 91, 553-560.

Gallagher, T., Richardson, C.A., Seed, R., Jones, T., 2008. The seasonal movement and abundance of the starfish, Asterias rubens in relation to mussel farming practice: A case study from the Menai Strait, UK. Journal of Shellfish Research 27, 1209-1215. doi:10.2983/0730-8000-27.5.1209

Galtsoff, P.S., Loosanoff, V.L., 1939. Natural history and methods of controlling the starfish (Asterias forbesi, Desor). U.S. Bureau of Fisheries 31, 75-132.

Giese, A.C., 1966. On the biochemical constitution of some echinoderms, in: Boolootian, R.A. (Ed.), Physiology of Echinodermata. John Wiley \& Sons, New York, pp. 757-796.

Guillou, M., 1996. Biotic and abiotic interactions controlling starfish outbreaks in the Bay of Douarnenez, Brittany, France. Oceanologica Acta 19, 415-420.

Hancock, D.A., 1955. The feeding behaviour of starfish on Essex oyster beds. Journal of the Marine Biological Association of the U.K. 34,313-331.

Himmelman, J.H., Dutil, C., Gaymer, C.F., 2005. Foraging behavior and activity budgets of sea stars on a subtidal sediment bottom community. Journal of Experimental Marine Biology and Ecology 322, 153-165.

Hummel, C., Honkoop, P., Van der Meer, J., 2011. Small is profitable: No support for the optimal foraging theory in sea stars Asterias rubens foraging on the blue edible mussel Mytilus edulis. Estuarine, Coastal and Shelf Science 94, 89-92.

Inglis, G.J., Gust, N., 2003. Potential indirect effects of shellfish culture on the reproductive success of benthic predators. Journal of Applied Ecology 40, 1077-1089.

Kamermans, P., Blankendaal, M., Perdon, J., 2009. Predation of shore crabs (Carcinus maenas (L.)) and starfish (Asterias rubens L.) on blue mussel (Mytilus edulis L.) seed from wild sources and spat collectors. Aquaculture 290, 256-262. doi:10.1016/j.aquaculture.2009.02.031

Lee, C.F., 1951. Starfish Control - The Economic Necessity and Methods Used, in: Technological Studies of the Starfish - Fisheries Leaflet 391. Fish and Wildlife Service United States Department of the Interior, Washington, D. C., pp. 1-6.

McQuaid, N., Roberts, D, McMinn, L., Browne, L., McDonough, N., 2007. A multi-disciplinary study of the blue mussel seed resource in the north Irish Sea and ongrowing strategies for the Northern Ireland bottom mussel industry. Centre for Marine Resources and Mariculture, Belfast.

Miron, G., Audet, D., Landry, T., Moriyasu, M., 2005. Predation potential of the invasive green crab (Carcinus maenas) and other common predators on commercial bivalve species found on Prince Edward Island. Journal of Shellfish Research 24, 579-586. doi:10.2983/0730-8000(2005)24 
Nichols, D., Barker, M.F., 1984. A comparative study of reproductive and nutritional periodicities in two populations of Asterias rubens (Echinodermata: Asteroidea) from the English Channel. Journal of the Marine Biological Association of the UK 64, 471-484.

Paine, R.T., 1966. Food Web Complexity and Species Diversity. The American Naturalist 100, 65.

R Core Team, 2012. R: A language and environment for statistical computing. R Foundation for Statistical Computing, Vienna, Austria.

Saier, B., 2001. Direct and indirect effects of seastars Asterias rubens on mussel beds (Mytilus edulis) in the Wadden Sea. Journal of Sea Research 46, 29-42.

Scheiner, S.M., 2001. Theories, Hypotheses and Statistics, in: Scheiner, S.M., Gurevitch, J. (Eds.), Design and Analysis of Ecological Experiments. Oxford Univeristy Press, Oxford, pp. 3-13.

Simes, R.J., 1986. An improved bonferroni procedure for multiple tests of significance. Biometrika $73,751-754$.

Sloan, N.A., 1980. Aspects of the feeding biology of asteroids. Oceanography and Marine Biology Annual Review 18, 57-124.

Sloan, N.A., Aldridge, T.H., 1981. Observations on an aggregation of the starfish Asterias rubens L. in Morecambe Bay, Lancashire, England. Journal of Natural History 15, 407-418.

Smaal, A.C., 2002. European mussel cultivation along the Atlantic coast: Production status, problems and perspectives. Hydrobiologia 484, 89-98.

Smith, G.F.M., 1940. Factors limiting distribution and size in the starfish. Journal of the Fisheries Reserach Board of Canada 5, 84-103.

Sommer, U., Meusel, B., Stielau, C., 1999. An experimental analysis of the importance of body-size in the seastar-mussel predator-prey relationship. Acta Oecologica 20, 81-86. doi:http://dx.doi.org/10.1016/S1146-609X(99)80019-8

Uthicke, S., Schaffelke, B., Byrne, M., 2009. A boom-bust phylum? Ecological and evolutionary consequences of density variations in echinoderms. Ecological Monographs 79, 3-24.

Ventura, C.R.R., Falcao, A.P.C., Santos, J.S., Fiori, C.S., 1997. Reproductive cycle and feeding periodicity in the starfish Astropecten brasiliensis in the Cabo Frio upwelling ecosystem (Brazil). Invertebrate Reproduction \& Development 31, 135-141.

Vevers, H.G., 1949. The biology of Asterias rubens L.: Growth and Reproduction. Journal of the Marine Biological Association of the United Kingdom 28, 165-187.

Zuur, A.F., Ieno, E.N., Walker, N., Saveliev, A.A., Smith, G.M., 2009. Mixed effects models and extensions in ecology with R, Statistics. Springer, New York. doi:10.1007/978-0-387-87458-6

\section{Tables and Figures}


Table 1 Number of tows from which video data and starfish measurements were collected during the sampling period

Table 2 ANOVA testing the effect of date of mopping and size of mussels on the density of Asterias rubens observed in video footage, the density of A. rubens collected on mops and the efficiency of starfish mops. Significant results $(\mathrm{p}<0.05)$ are highlighted in bold text.

Figure 1 GoPro $^{\mathrm{TM}}$ camera on the starfish mop deployed from the starboard side of a mussel dredger in Belfast Lough.

Figure 2 Northeast coast of Ireland showing Belfast Lough

Figure 3 Size density distributions of Asterias rubens from starfish mops deployed on mussel beds during each sampling period (A. Oct 2013; B. Jan 2014; C. Mar 2014; D. Apr 2014; E. May 2014; F. Jul 2014; G. Oct 2014; H. Nov 2014; I. Dec 2014) in Belfast Lough. Lower case letters represent populations that are statistically indistinguishable from each other $(\mathrm{p}>0.05)$.

Figure 4 Size density distributions of Asterias rubens collected from starfish mops deployed on mussel beds with mussels of different sizes (A. 2000 mussels kg-1; B.1500 mussels kg-1; C. 1350 mussels kg-1; D. 800 mussels kg-1; E. 600 mussels kg-1; F. 70 mussels kg-1) in Belfast Lough.

Figure 5 A. Mean Gonad Index $(\% \pm$ SE) and B. Mean Pyloric Caeca Index $(\% \pm$ SE) of Asterias rubens $(\mathrm{n}=20)$ at Belfast Lough during 2014. Lower case letters represent populations that are statistically indistinguishable from each other $(\mathrm{p}>0.05)$. 
Figure 6 Mean $( \pm \mathrm{SE})$ density of Asterias rubens estimated from video footage (solid line), the density of Asterias rubens collected by starfish mops (dotted line) and the efficiency of the mop at collecting starfish (dot and dashed line) from Belfast Lough over time

Figure 7 Mean $( \pm$ SE) density of Asterias rubens estimated from video footage (solid line), the density of Asterias rubens collected by starfish mops (dotted line) and the efficiency of the mop at collecting starfish (dot and dashed line) from Belfast Lough on mussel beds with mussels of different sizes.

Figure 8 The log-linear relationship between the density of Asterias rubens seen on video footage compared to the density collected by a starfish mop deployed in Belfast Lough 

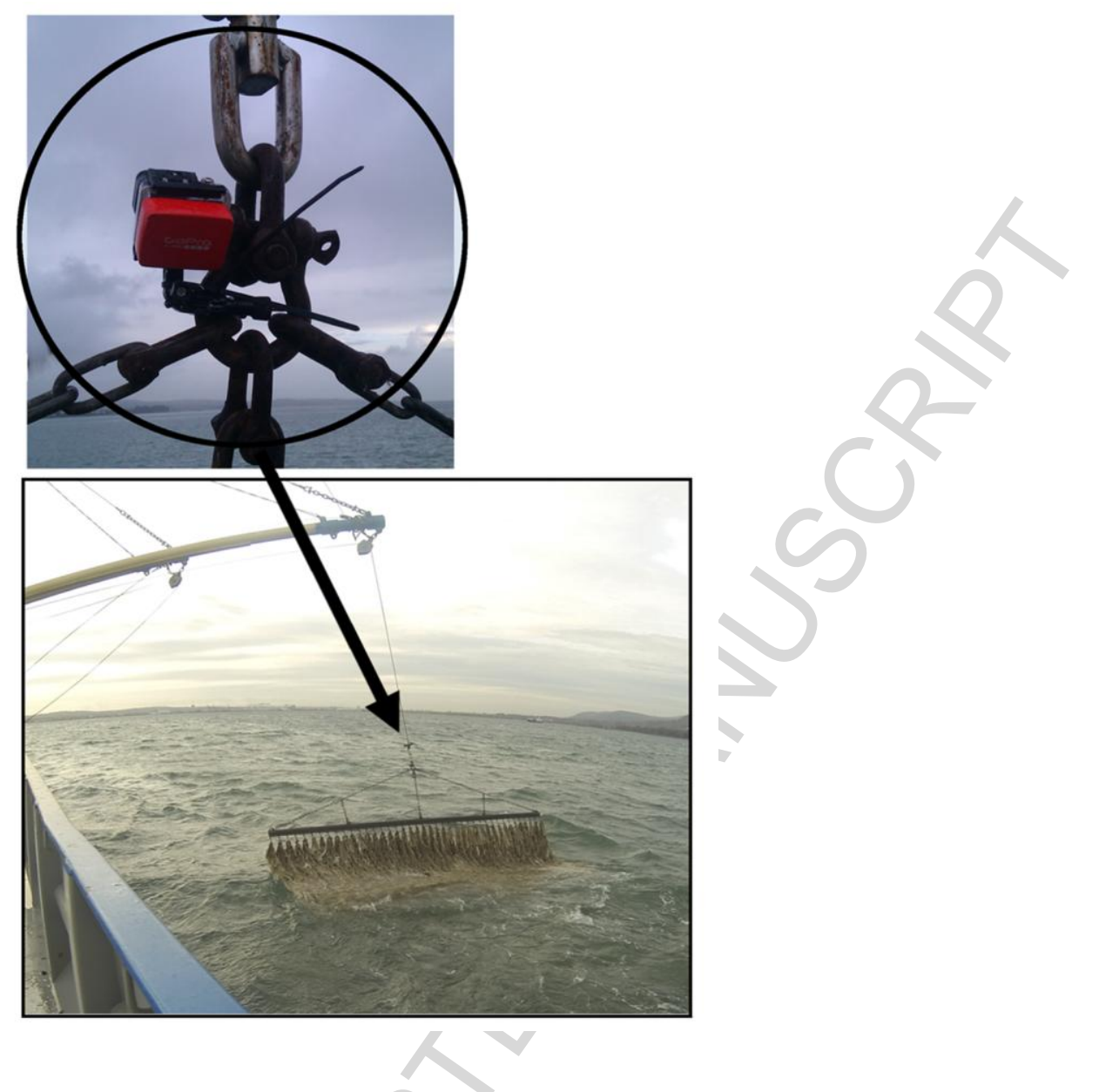

Fig. 1 


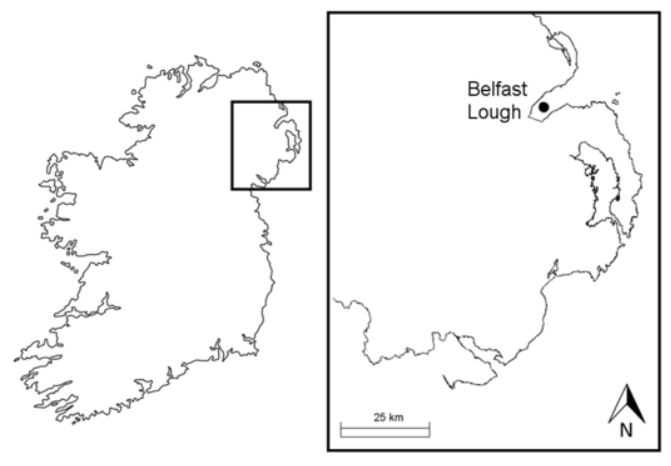

Fig. 2 

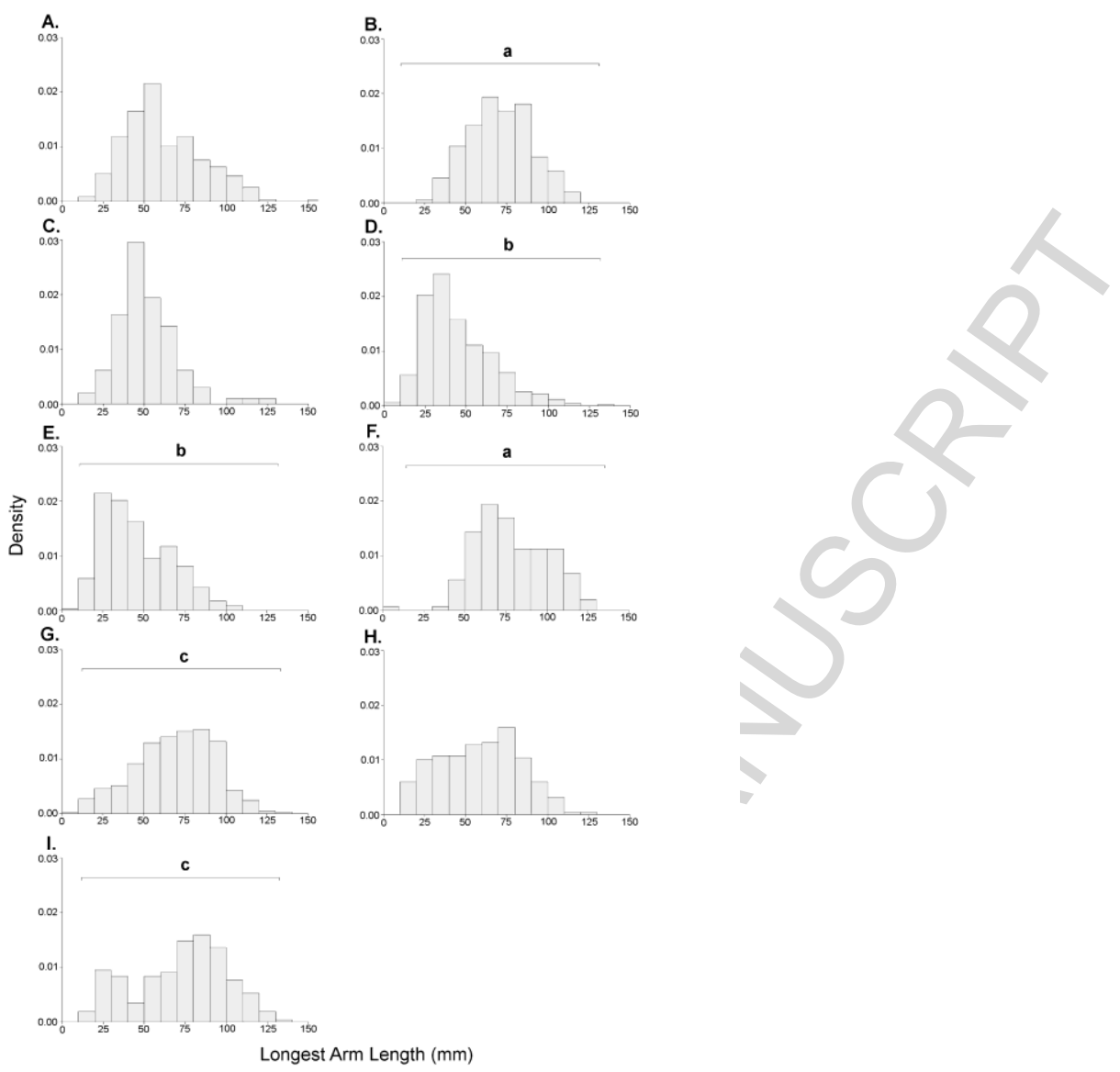

Fig. 3

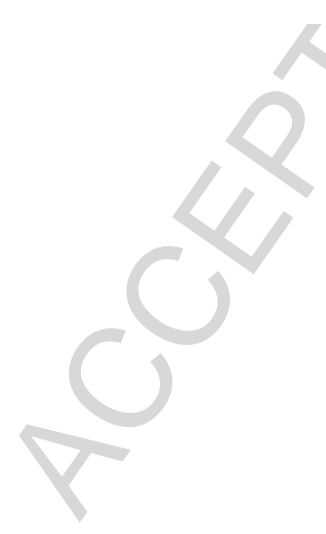


A.

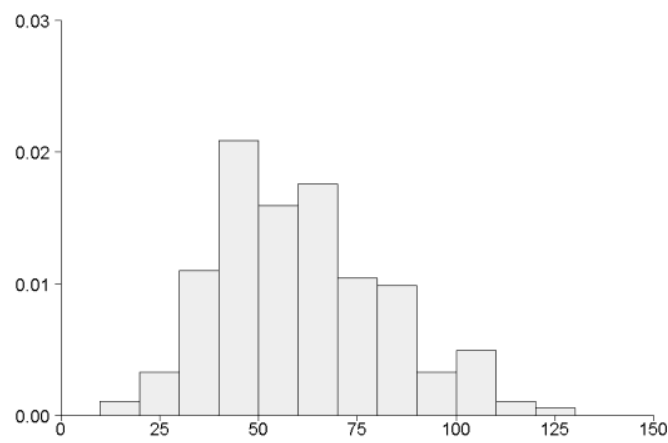

c.

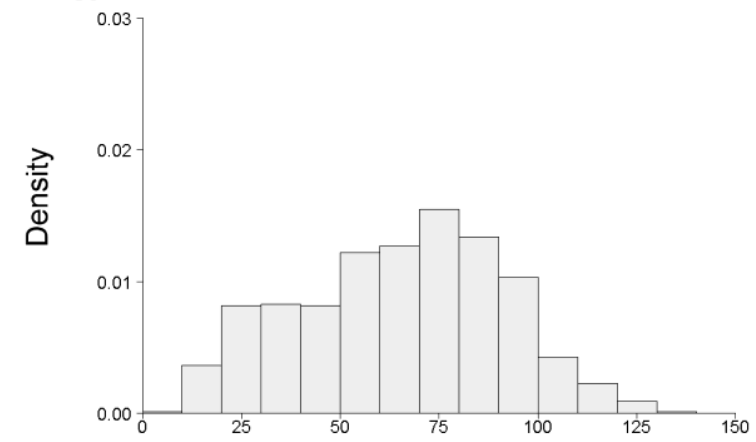

E.

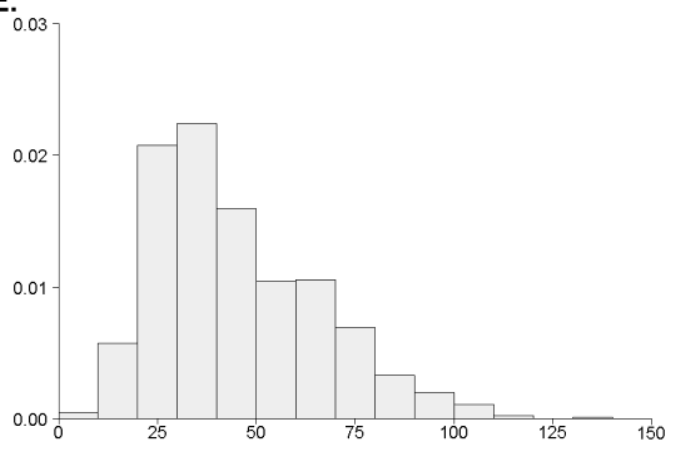

B.

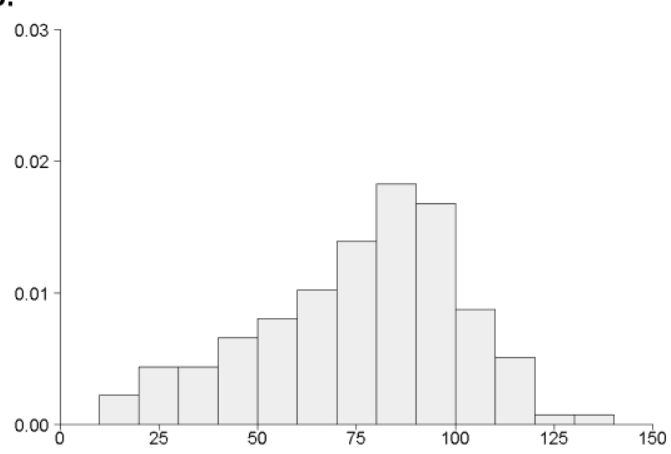

D.

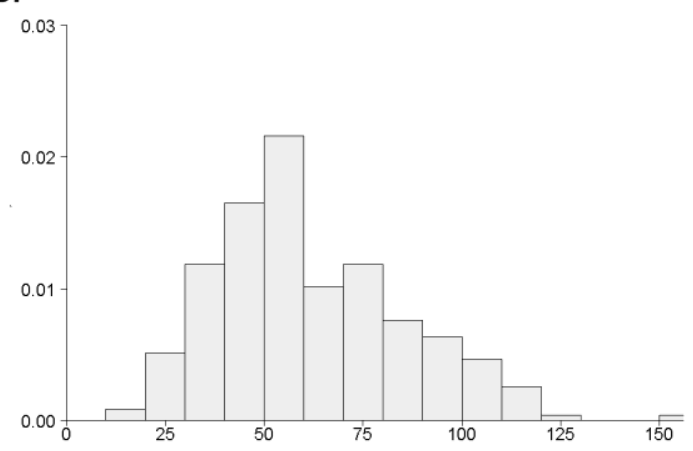

F.

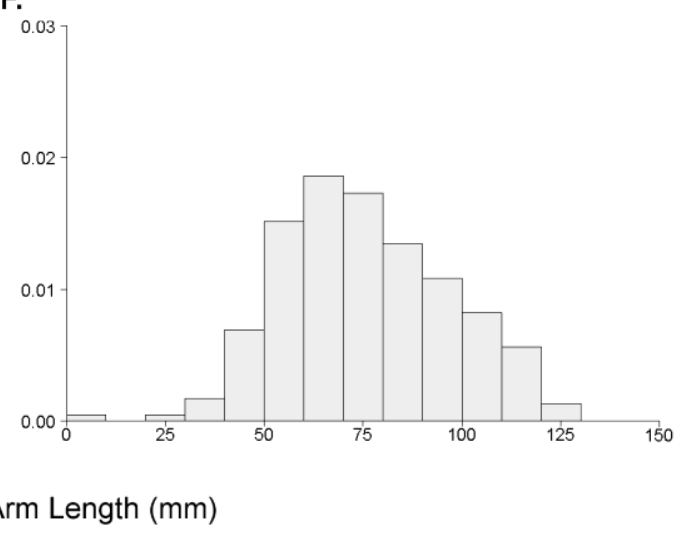

Fig. 4 

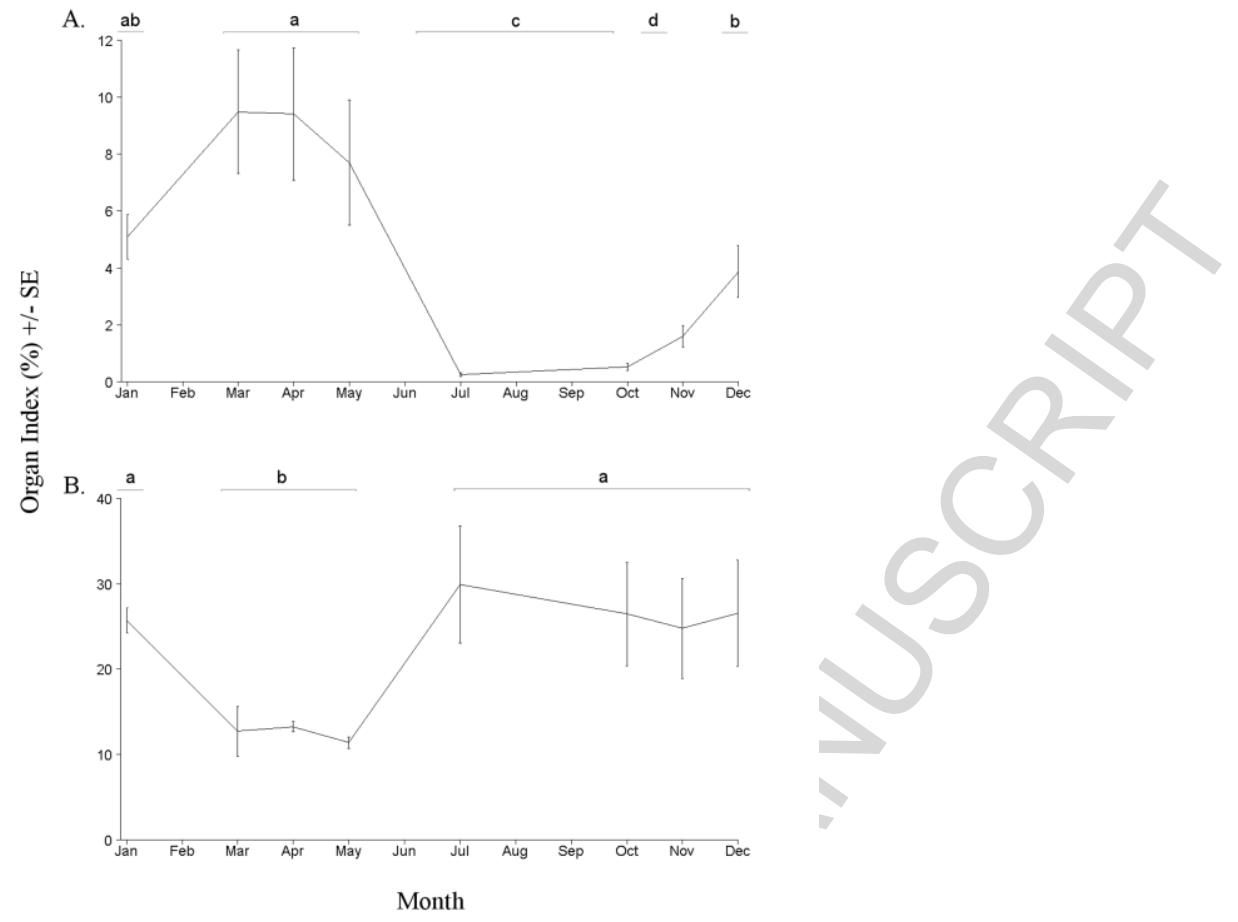

Fig. 5 


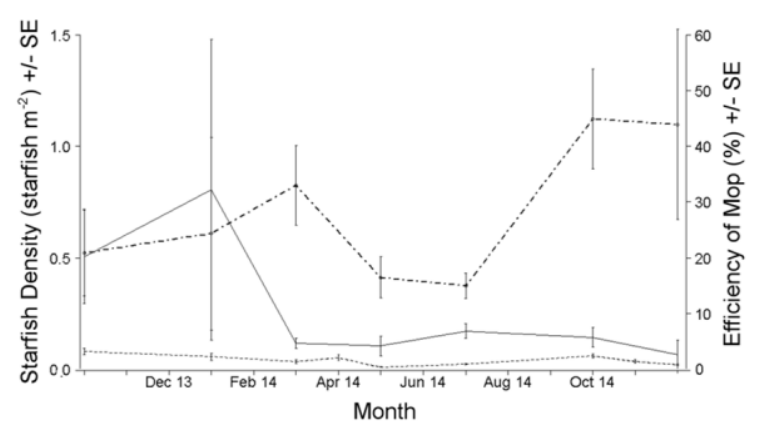

Fig. 6 


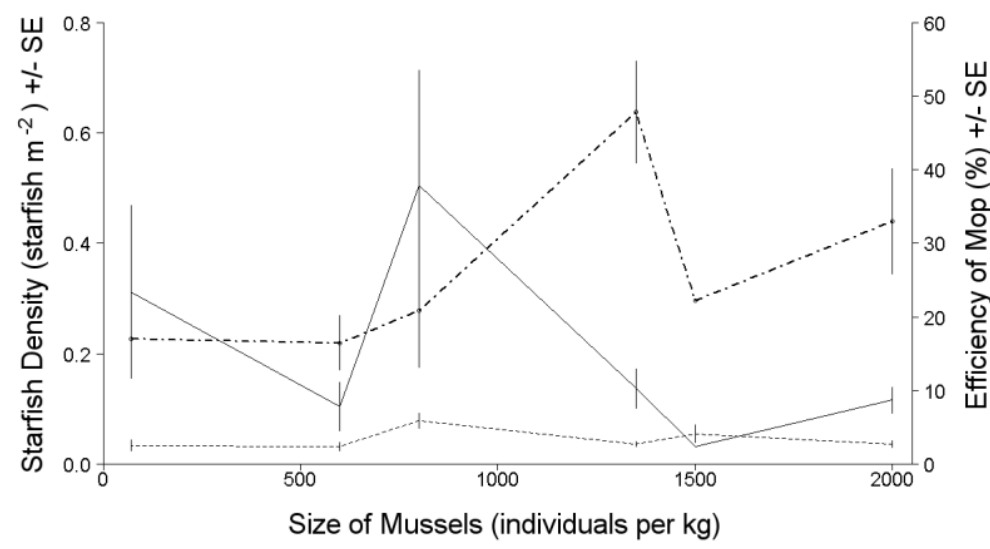

Fig. 7 


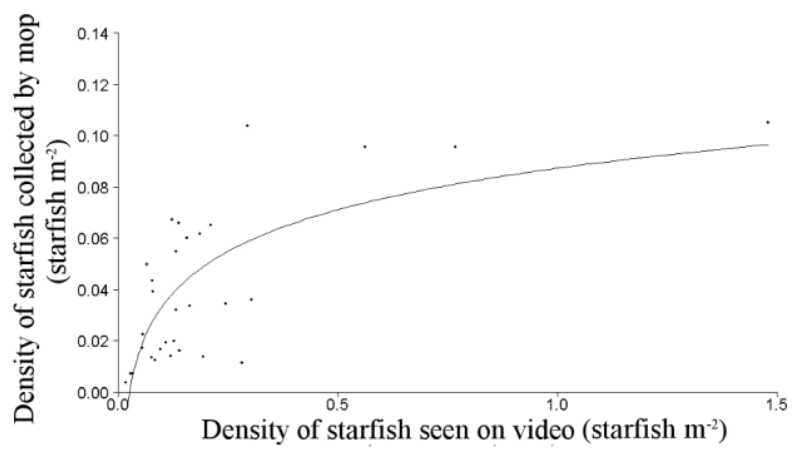

Fig. 8 
Table 1 Number of tows from which video data and starfish measurements were collected during the sampling period

\begin{tabular}{ccc}
\hline Date of Mopping & $\begin{array}{c}\text { Number of tows from which } \\
\text { video data was collected }\end{array}$ & $\begin{array}{c}\text { Number of tows from which starfish } \\
\text { measurements were collected }\end{array}$ \\
\hline $30 / 10 / 2013$ & 3 & 6 \\
$16 / 01 / 2014$ & 2 & 5 \\
$07 / 03 / 2014$ & 5 & 5 \\
$03 / 04 / 2014$ & 0 & 11 \\
$01 / 05 / 2014$ & 6 & 10 \\
$17 / 07 / 2014$ & 7 & 8 \\
$29 / 10 / 2014$ & 6 & 13 \\
$27 / 11 / 2014$ & 0 & 11 \\
$16 / 12 / 2014$ & 2 & 12 \\
\hline
\end{tabular}


Table 2 ANOVA testing the effect of date of mopping and size of mussels on the density of Asterias rubens observed in video footage, the density of A. rubens collected on mops and the efficiency of starfish mops. Significant results $(\mathrm{p}<0.05)$ are highlighted in bold text.

\begin{tabular}{llllll}
\hline Source of variation & Dependent variable & DF & MS & F & p \\
\hline Date of mopping & $\begin{array}{l}\text { Density of starfish } \\
\text { observed on videos }\end{array}$ & 6 & 0.353 & 3.009 & $\mathbf{0 . 0 2 5}$ \\
& $\begin{array}{l}\text { Density of starfish } \\
\text { collected from mops }\end{array}$ & 8 & 0.658 & 8.761 & $<\mathbf{0 . 0 0 1}$ \\
& Efficiency of mops & 6 & 0.206 & 3.501 & $\mathbf{0 . 0 1 2}$ \\
Size of mussels on & $\begin{array}{l}\text { Density of starfish } \\
\text { mussel bed }\end{array}$ & 5 & 0.398 & 3.370 & $\mathbf{0 . 0 1 8}$ \\
& $\begin{array}{l}\text { Denserved on videos } \\
\text { collected from mops }\end{array}$ & & & & \\
& Efficiency of mops & 5 & 0.261 & 4.881 & $\mathbf{0 . 0 0 3}$ \\
\hline
\end{tabular}




\section{Statement of relevance}

Starfish mops are often utilised during benthic mussel cultivation where predation from starfish threatens mussel crops. Although mops appear to remove starfish from mussel beds there is uncertainty as to their exact effectiveness and there is scope to enhance efficiency of this predator removal technique. This research used a novel method of attaching GoPro cameras to starfish mops deployed from mussel dredgers to investigate the effectiveness of starfish mops in removing predatory starfish from commercial mussel beds. This work was the first study conducted to assess the effectiveness of this predator removal technique since the 1940s and the use of underwater video footage gives greater insight into the efficiency of starfish mops as a predator removal technique for use within bivalve aquaculture.

We found efficiency of starfish mops varied temporally and discovered a density dependent relationship between the efficiency of starfish mops and the density of starfish encountered. These findings have particular relevance to on-growing of mussels in benthic cultivation in addition to the culture of other bivalve species. By providing insight into the ecology of starfish feeding on mussel beds and furthering knowledge on how best to remove predatory starfish species from the seabed in areas where they could affect the output from mussel fisheries this research is highly relevant to mussel cultivators. 


\section{Highlights}

- We investigated the effectiveness of starfish mops to remove predators on commercial mussel beds.

- Starfish mops reduced starfish numbers by a mean of $27 \%$ ( \pm SE 3.2).

- There was a density dependent relationship between mop efficiency and starfish densities.

- Area covered by mops should be minimised when starfish densities are high to maintain efficiencies. 